\title{
Clones and Clusters of Antimicrobial-Resistant Klebsiella from
}

\section{Southwestern Nigeria}

Ayorinde O. Afolayan ${ }^{1}$, Anderson O. Oaikhena ${ }^{1}$. Aaron O. Aboderin ${ }^{2}$, Olatunde F. Olabisi ${ }^{2}$, Adewale

A. Amupitan ${ }^{2}$, Oyekola V. Abiri², Veronica O. Ogunleye ${ }^{3}$, Anthony Underwood $^{5}$, Erkison

Ewomazino Odih ${ }^{1}$, Abolaji T. Adeyemo ${ }^{4}$, Adeyemi T. Adeyemo ${ }^{2}$, Temitope O. Obadare ${ }^{2}$, Sophia

David $^{5}$, Silvia Argimón ${ }^{5}$, Monica Abrudan ${ }^{5}$, Abiodun Egwuenu ${ }^{6}$, Chikwe Ihekweazu ${ }^{6}$, David M.

Aanensen ${ }^{5}$, Iruka N. Okeke ${ }^{1}$ and the NIHR Global Health Research Unit (GHRU) on Genomic

Surveillance of Antimicrobial Resistance ${ }^{\mathrm{a}}$

${ }^{1}$ Global Health Research Unit on Genomic Surveillance of Antimicrobial Resistance, Department of Pharmaceutical Microbiology, Faculty of Pharmacy, University of Ibadan, Oyo State, Nigeria.

${ }^{2}$ Department of Medical Microbiology and Parasitology, Obafemi Awolowo University, Ile-Ife, Osun State, Nigeria.

${ }^{3}$ University College Hospital, Ibadan, Oyo State, Nigeria.

${ }^{4}$ Department of Medical Microbiology and Parasitology, LAUTECH Teaching Hospital, Osogbo,

Nigeria. LAUTECH Teaching Hospital, Osogbo, Nigeria

${ }^{5}$ Centre for Genomic Pathogen Surveillance, Big Data Institute, University of Oxford, Old Road

Campus, Oxford, United Kingdom and Wellcome Genome Campus, Hinxton, UK

${ }^{6}$ Nigeria Centre for Disease Control, Jabi, Abuja, Nigeria.

${ }^{a}$ Members of the NIHR Global Health Research Unit on Genomic Surveillance of Antimicrobial Resistance are listed in the Acknowledgments.

Keywords: Klebsiella, Genomic Surveillance, Antimicrobial Resistance, Nigeria

Running title: AMR Klebsiella from southwestern Nigeria 
bioRxiv preprint doi: https://doi org/10.1101/2021.06.21449255; this version posted June 24,2021 . The copyright holder for this preprint (which was not certified by peer review) is the author/funder, who has granted bioRxiv a license to display the preprint in perpetuity. It is made available under aCC-BY 4.0 International license.

Corresponding author: Iruka N. Okeke, Global Health Research Unit for the Genomic Surveillance of Antimicrobial Resistance, Department of Pharmaceutical Microbiology, Faculty of Pharmacy, University of Ibadan, Oyo State, Nigeria. Email: iruka.n.okeke@gmail.com.

Alternate corresponding author: Ayorinde O. Afolayan, Global Health Research Unit on Genomic Surveillance of Antimicrobial Resistance, Department of Pharmaceutical Microbiology, Faculty of Pharmacy, University of Ibadan, Oyo State, Nigeria. Email: afolayanayorinde@gmail.com.

40-word summary: We performed whole genome sequencing (WGS) of 141 Klebsiella isolated in 2016-2018 at 3 antimicrobial-resistance (AMR) sentinel surveillance tertiary hospitals in southwestern Nigeria. This study uncovered known and novel K. pneumoniae lineages circulating in Nigeria that include multidrug-resistant ESBL producers. 


\section{ABSTRACT}

Introduction: Klebsiella pneumoniae is a World Health Organization high-priority antibioticresistant pathogen. However, little is known about the population structure and evolution of Klebsiella circulating in Nigeria.

Methods: We performed whole genome sequencing (WGS) of 141 Klebsiella isolated between 2016 and 2018 from clinical specimens at 3 antimicrobial-resistance (AMR) sentinel surveillance tertiary hospitals in southwestern Nigeria. We conducted in silico multilocus sequence typing, AMR gene, virulence gene, plasmid, and $\mathrm{K}$ and $\mathrm{O}$ loci profiling, as well as phylogenetic analyses, using publicly available tools and Nextflow pipelines.

Results: Phylogenetic analysis revealed that the majority of the $134 \mathrm{~K}$. pneumoniae and $5 \mathrm{~K}$. quasipneumoniae isolates from Nigeria characterized are closely related to globally disseminated multidrug-resistant clones. Of the 39 K. pneumoniae sequence types (STs) identified, the most common were ST307 (15\%), ST5241 (12\%), ST15 ( 9\%), and ST25 ( 6\%). ST5241, one of 10 novel STs detected, is a single locus variant of ST636 carrying $d f r A 14$, tetD, qnrS, and oqxAB resistance genes. The extended-spectrum $\beta$ lactamase (ESBL) gene $b l a_{\mathrm{CTX} \_\mathrm{M}-15}$ was seen in $72 \%$ of $K$. pneumoniae genomes, while $8 \%$ encoded a carbapenemase. Four likely outbreak clusters from one facility, within STs 17, 25, 307, and 5241, were ESBL but not carbapenemase-bearing clones. Conclusion: This study uncovered known and novel K. pneumoniae lineages circulating in Nigeria that include multidrug-resistant ESBL producers. Carbapenemase-producing isolates remain uncommon. WGS retrospectively identified outbreak clusters, pointing to the value of genomic approaches in AMR surveillance for improving infection prevention and control in Nigerian hospitals. 


\section{ABBREVIATIONS}

OAU: Obafemi Awolowo University Teaching Hospital

NCDC: Nigeria Centre for Disease Control

LAU: Ladoke Akintola University Teaching Hospital

UCH: University College Hospital

GLASS: Global Antimicrobial Resistance Surveillance System

AMR: Antimicrobial resistance

ENA: European Nucleotide Archive

WGS: Whole Genome Sequencing

CLSI: Clinical \& Laboratory Standards Institute

ESBL: Extended Spectrum beta-lactamase

\section{FUNDING}

This work was supported by Official Development Assistance (ODA) funding from the National Institute of Health Research [16/136/111: NIHR Global Health Research Unit on Genomic Surveillance of Antimicrobial Resistance].

This research was commissioned by the National Institute of Health Research using Official Development Assistance (ODA) funding. INO is an African Research Leader supported by the UK Medical Research Council (MRC) and the UK Department for International Development (DFID) under the MRC/DFID Concordat agreement that is also part of the EDCTP2 program supported by the European Union. The funders had no role in the content, crafting or submission of this paper. The views expressed in this publication are those of the authors and not necessarily those of the funders or their affiliates.

\section{CONFLICT OF INTEREST}


bioRxiv preprint doi: https://doi.org/10.1101/2021.06.21.449255; this version posted June 24, 2021. The copyright holder for this preprint (which was not certified by peer review) is the author/funder, who has granted bioRxiv a license to display the preprint in perpetuity. It is made available under aCC-BY 4.0 International license.

The authors: No reported conflicts of interest. All authors have submitted the ICMJE Form for

Disclosure of Potential Conflicts of Interest. 


\section{Main manuscript}

\section{INTRODUCTION}

Klebsiella is a ubiquitous gram-negative genus that can cause a variety of opportunistic infections [1, 2]. Klebsiella pneumoniae, the species most commonly associated with human disease, is frequently implicated in life-threatening bacteremia and sepsis arising from translocations from non-sterile niches or medical devices in hospitals [3]. Although the precise burden of infectious diseases resulting from Klebsiella spp. is unknown in Africa, there is an upward trend in reports of K. pneumoniaeassociated bloodstream infections, including from Nigeria, Côte d'Ivoire, Malawi, Gambia, and South Africa [4-8]. There have also been isolated case reports of non-pneumoniae infections in Nigeria [9]. Altogether, these infections have high mortality rates and incur high costs [10, 11]. Rigorous surveillance of Klebsiella clones circulating within Nigerian hospitals and communities is needed to inform treatment guidelines and prioritize AMR interventions. Whole genome sequencing (WGS) offers the attractive prospect of meeting this need within local resource constraints. WGS tools also provide taxonomic resolution below serotype levels, a feat impossible in resource-limited settings by classical typing methods [13]. Mapping the diversity of Klebsiella populations at high resolution, with spatiotemporal dynamics, also makes it possible to elucidate the origin and dissemination of AMR $[12,13]$.

In contrast to similarly constrained settings elsewhere in Africa [14-16], few Nigeria reports include in-depth analysis of more than a handful of Klebsiella isolates. For example, as of the time of writing, Pathogenwatch, which sources its public genomes from ENA, includes only 109 Klebsiella genomes from Nigeria [17]. Nigeria recently initiated national AMR surveillance following commissioning of a 2017 National Action Plan, and the Nigeria Centre for Disease Control (NCDC) enrolled the country in the WHO's Global Antimicrobial Resistance Surveillance System (GLASS) [18]. NCDC is building a network that currently consists of 9 AMR sentinel hospital laboratories and 2 national reference laboratories [19]. The very low number of Klebsiella genomes from Nigeria compelled the 
Nigeria node of the Global Health Research Unit (GHRU) on Genomic Surveillance of AMR, which provides WGS services to the reference laboratories, to collect and sequence retrospective isolates. In addition to increasing the number of relevant genomes in publicly available databases that can support prospective surveillance, this study aimed to understand the population structure, evolution, pathogenicity, and transmission dynamics of this critical-priority pathogen circulating in southwestern Nigeria.

\section{METHODS}

\section{Ethical Considerations}

Most genomes included in this study were acquired from surveillance without linked patient data. We additionally integrated data from the Obafemi Awolowo University (OAU) Teaching Hospital sentinel site, as approved by the Ethics and Research Committee, Obafemi Awolowo University Teaching Hospitals Complex with registration number ERC/2017/05/06.

\section{GHRU Nigeria Workflow}

Strains, re-identification, and antimicrobial susceptibility testing: The NCDC, Nigeria's AMR surveillance coordinating center, requested from the network cryopreserved invasive isolates (from blood, cerebrospinal fluid, and urine) from 2016-2018, to develop a local genome database. Sentinel laboratories provided the national reference laboratory with strains and information on species identity, clinical diagnosis, and antimicrobial susceptibility tests (AST) via WHONET [20]. At the national reference laboratory, in collaboration with the GHRU, isolate identification and AST were validated using the VITEK system (version 2.0), testing, as appropriate, amikacin, gentamicin, ampicillin, amoxicillin/clavulanic acid, piperacillin/tazobactam, cefuroxime, cefuroxime_axetil, cefepime, ceftriaxone, cefoperazone/sulbactam, nitrofurantoin, nalidixic acid, ciprofloxacin, ertapenem, imipenem, meropenem, trimethoprim-sulphamethoxazole, colistin, and tigecycline [21]. Antimicrobial susceptibility test results were interpreted in line with the CLSI standards [22]. 
bioRxiv preprint doi: https://doi org/10.1101/2021.0621449255; this version posted June 24 2021. The copyright holder for this preprint (which was not certified by peer review) is the author/funder, who has granted bioRxiv a license to display the preprint in perpetuity. It is made available under aCC-BY 4.0 International license.

DNA extraction, Library Preparation, and Sequencing: Genomic DNA was extracted using the Wizard DNA extraction kit (Promega; Wisconsin, USA; Cat. No: A1125). DNA was quantified using a dsDNA Broad Range fluorometric quantification assay (Invitrogen; California, USA; Cat. No: Q32853). Double-stranded DNA libraries (avg. 500 bp) were prepared using the Covaris LC220 for fragmentation, and NEBNext Ultra II FS DNA library kit for Illumina with 384-unique indexes (New England Biolabs, Massachusetts, USA; Cat. No: E6617L). Libraries were sequenced using the HiSeq X10 with 150 bp paired-end chemistry (Illumina, CA, USA).

Genome assembly: Genome assembly was carried out according to the GHRU protocol (https://www.protocols.io/view/ghru-genomic-surveillance-of-antimicrobial-resista-bpn6mmhe).

Parameters for post-assembly quality checks include the total genome size (between $4584497 \mathrm{bp}$ to 7012008 bp), N50 score (> 25000), contaminant level $(<5 \%)$, and number of contigs $(<300)$. Only Klebsiella genomes that passed all quality checks $($ K. pneumoniae, $\mathrm{n}=134 ;$ K. quasipneumoniae, $\mathrm{n}=$ 5) were selected for downstream analysis.

\section{Single Nucleotide Polymorphism (SNP) Analysis}

Sequence reads were mapped to the reference genome of the K. pneumoniae strain NTUH-K2044 (Genbank Accession number GCF_009497695.1) to determine evolutionary relationships among the isolates according to GHRU protocol (https://www.protocols.io/view/ghru-genomic-surveillance-ofantimicrobial-resista-bpn6mmhe). Pairwise SNP distances for likely outbreak isolates from OAU were calculated from the pseudo-genome alignment using FastaDist (https://gitlab.com/antunderwood/fastadist). Outbreak isolates belonging to STs 17, 25, and 307 were aligned to reference genomes NZ_CP009461.1, NZ_CP031810.1, and NZ_CP022924.1 respectively, selected with Bactinspector (https://gitlab.com/antunderwood/bactinspector/). The ST636 reference EuSCAPE_UK136 was selected from Pathogenwatch collections, being the only known single locus variant of ST5241.

Prediction of AMR Determinants, Virulence Factors, and Plasmid Profiling 
bioRxiv preprint doi: https://doi org/10.1101/2021.06.21449255; this version posted June 24 2021. The copyright holder for this preprint

(which was not certified by peer review) is the author/funder, who has granted bioRxiv a license to display the preprint in perpetuity. It is made available under aCC-BY 4.0 International license.

AMR determinants and plasmid replicons were predicted in accordance with the aforementioned

GHRU protocol. omp mutations, virulence score, and acquired virulence genes were determined using Kleborate (v2.0.0; https://github.com/katholt/Kleborate) [23, 24].

\section{Concordance Analysis}

Concordance between phenotypic and genotypic AMR for aminoglycosides, $\beta$-lactams, carbapenem, cephalosporin, quinolone, and trimethoprim was determined by using https:/gitlab.com/-

/snippets/2050300 based on a protocol

(https://glcdn.githack.com/cgps/ghru/ghrur/raw/master/docs/articles/simple concordance example.ht

ml) that employs the epi.tests function of the epiR package to calculate sensitivity and specificity with confidence bounds.

\section{Identification of Multilocus Sequence Types.}

Multilocus sequence types (MLSTs) according to the Pasteur scheme were determined by following the aforementioned GHRU protocol (https://www.protocols.io/view/ghru-genomic-surveillance-ofantimicrobial-resista-bpn6mmhe) [25]. We also used Kleborate (v2.0.0;

https://github.com/katholt/Kleborate) to identify the ST most closely related to novel STs (in terms of locus variants).

\section{Availability of Sequence Data}

Raw sequence datasets generated during this study have been deposited in the ENA with bioproject number PRJEB29739 (https://www.ebi.ac.uk/ena/browser/view/PRJEB29739). Accessions are available in Supplementary Table 3.

\section{RESULTS}

Epidemiology, Sequence Types, Virulence-Associated Determinants, and AMR Determinants of Klebsiella from Southwestern Nigeria Hospitals 
Retrospective Klebsiella isolates were collected from 3 hospitals that had archival isolates: Obafemi Awolowo University Teaching Hospital (OAU, Ile-Ife, Osun State, Nigeria; n = 92), University College Hospital (UCH, Ibadan, Oyo State, Nigeria; $\mathrm{n}=30$ ), and Ladoke Akintola University Teaching Hospital (LAU, Oshogbo, Osun State, Nigeria; $n$ =12). Of the 134 isolates, 87 were from blood, comprising 45 from OAU, 30 from $\mathrm{UCH}$, and 12 from LAU. We additionally sequenced 47 non-blood isolates from OAU, recovered from urine $(\mathrm{n}=37)$, ocular $(\mathrm{n}=2)$, stool $(1)$, throat $(\mathrm{n}=2)$, and rectal $(\mathrm{n}=5)$ swabs.

Of the 134 genomes confirmed as K. pneumoniae by WGS, 18 (13\%) and 33 (25\%) were identified by reference laboratory VITEK and the sentinel laboratories, respectively, as either other members of the Enterobacteriaceae family, Acinetobacter baumannii, or Pseudomonas aeruginosa (Supplementary Table 1). All WGS-identified Klebsiella quasipneumoniae isolates were identified either as K. pneumoniae or Enterobacter complexes by VITEK and the sentinel laboratories, respectively (Supplementary Table 1). The phylogenetic tree, epidemiological data, and analyses data can be visualized in Microreact for retrospective Klebsiella pneumoniae (https://microreact.org/project/GHRUNigeriaKpneumoniae/2a856694), and OAU outbreak isolates (ST17: https://microreact.org/project/brfq17BXzwmqptfcrNRfZR/71b2f0f1; ST25:

https://microreact.org/project/8FP4F1D5fSQMv6FDxbR39b/bd381f0b; ST307:

https://microreact.org/project/sV5NsJ8szcorvFAeFQgV4E/6498edf1; ST5241: https://microreact.org/project/u5RPX7CjyitjRYMQ9ByW4W/1a3570e2).

Overall, the K. pneumoniae isolates sequenced in this study belonged to 39 different sequence types (STs), with ST307, ST5241, ST15, and ST25 being most common (Figure 1). Only 4 STs (ST15, ST101, ST147, and ST307) were found across the 3 sentinel sites (Figure 1). Klebsiella quasipneumoniae genomes $(\mathrm{n}=5)$ belonged to 4 STs: ST1602, ST2133, ST5250 ( $\mathrm{n}=1$ each), and $\operatorname{ST} 5249(n=2)$.

We identified few virulence genes associated with invasiveness, including yersiniabactin ( $y b t$ genes and fyuA; $\mathrm{n}=42,31.34 \%$ ), aerobactin (iuc; $\mathrm{n}=2$ ), salmochelin (iro; $\mathrm{n}=2$ ), and capsule expression upregulators $\operatorname{rmp} A D C$ and $\operatorname{rmp} A 2(\mathrm{n}=2)$. Only 2 ST86 isolates had a virulence score of 3 , the highest 
recorded in our collection. No acquired K pneumoniae virulence gene was detected in novel ST5241 (Figure 2), nor in the non-pneumoniae Klebsiella species.

We detected 33 different phenotypically-defined K (capsular) loci from the invasive K. pneumoniae isolates sequenced, with KL102, KL123, KL2, KL62, and KL27 representing the 5 most common K loci (Supplementary Table 2). Eleven different $\mathrm{O}$ loci were detected among the invasive $K$. pneumoniae isolates recovered from bloodstream infections. Collectively, the $3 \mathrm{O}$ loci- O1v1, O2v2, and $\mathrm{O} 1 \mathrm{v} 2$ - accounted for more than $65 \%$ of the K. pneumoniae strains, and $\mathrm{O} 5$ was solely detected in ST5241 genomes.

Genes conferring resistance or reduced susceptibility to at least 5 antibiotic classes were detected in $116(86.6 \%)$ of $K$. pneumoniae genomes. Aside from core bla $_{S H V}$, these included8 $\beta$-lactamase genes, of which the extended-spectrum $\beta$-lactamase (ESBL) bla $a_{C T X-M-15}$ was by far the most common, present in $71.6 \%(\mathrm{n}=96)$ of the K. pneumoniae isolates belonging to 33 STs (Figure 2). As seen in other studies, we found this ESBL in strains with plasmids belonging to IncFIB_K ( $\mathrm{n}=70 / 96)$, IncFII_K ( $\mathrm{n}$ $=51 / 96)$, and IncR $(\mathrm{n}=43 / 96)$ incompatibility groups $[26,27]$. The bla $_{N D M-1}(\mathrm{n}=8 / 134)$, $\operatorname{lla}_{N D M-5}(\mathrm{n}=$ 2/134), and bla OXA-48 $(n=1 / 134)$ genes were the only carbapenemases detected, and these occurred in 8 STs, including ST392 (bla $\left.a_{N D M-1} ; \mathrm{n}=2\right)$, ST147/147-1-locus-variant $\left(b l a_{N D M-1} ; \mathrm{n}=2\right)$, ST530 (bla $a_{N D M-}$ $5 ; \mathrm{n}=2), \mathrm{ST} 43, \mathrm{ST} 15, \mathrm{ST} 307, \mathrm{ST} 716\left(\right.$ bla $_{N D M-1} ; \mathrm{n}=1$ each $)$, and ST219 $\left(\right.$ bla $\left._{O X A-48} ; \mathrm{n}=1\right)($ Figure 2). OmpK35 truncations were observed together with $b l a_{C T X-M-15}$ in 11 isolates and with bla $_{N D M-1}$ in 5 isolates. Altogether, 18 (13.5\%) K. pneumoniae strains carried carbapenemase genes, and/or ESBL genes plus porin defects known to confer carbapenem resistance [28]. Phenotypic antimicrobial susceptibility testing found 11 of 128 isolates carbapenem non-susceptible, and $\operatorname{bla}_{N D M-1}(\mathrm{n}=6)$, $b l a_{N D M-5}(\mathrm{n}=2)$, and/or $b l a_{C T X-M-15}$ and OmpK35 truncations $(\mathrm{n}=1)$ could account for nonsusceptibility in 9 of them (Figure 2). Concordance analysis showed that phenotypic AST and genotypic AMR gene prediction results agree substantially for carbapenems (concordance: $92.2 \%$; sensitivity: $82 \%$ [48.22\% - 97.72\%]; specificity: 93.2\% [86.97\% - 97\%]).

Reduced susceptibility to nalidixic acid $(n=70 / 125)$ or ciprofloxacin $(n=114 / 125)$ could be explained by the presence of one or more combinations of mutations in the quinolone resistance 
determining region $(\mathrm{QRDR})$ of $\operatorname{gyr} A$ and $\operatorname{parC}(\mathrm{n}=60)$, plasmid-mediated quinolone resistance genes (qnrS, qnrA, qnrB; $\mathrm{n}=82)$, and/or efflux-mediating mutations in $\operatorname{acr} R$ gene $(\mathrm{n}=98)($ Figure 2).

The 5 K. quasipneumoniae were resistant to phenicols, tetracyclines, sulphonamides, trimethoprim, and $\beta$-lactams (https://microreact.org/project/4f6Y56ECE979wkj8oDBhk2/dee16dac). One LAU isolate, collected 6 months after an outbreak of K. quasipneumoniae strains carrying bla $a_{N D M-5}$ in Abuja, Nigeria, was remotely related to those outbreak strains (SNP distance $\geq 235$ ), but, like the other 4 K. quasipneumoniae from the current study, it lacked carbapenemase genes [9].

\section{Retrospective Characterization of Possible Outbreaks}

Recovery dates for 74 of 92 isolates from the OAU facility were supplied. In under a year, between 6 and 14 isolates were recovered belonging to ST17, ST25, ST307, and ST5241. We noticed clusters of closely related isolates that were recovered within short periods, and we hypothesized that these might represent unreported/undetected outbreaks. Intra-cluster pairwise distances within the potential outbreak clades ranged from 1 to 3 SNPs, and inter-cluster pairwise distances within the same ST ranged from 46 to 370 . Temporally-clustered, closely-related clonal groups within each of the four STs (Figure 3), with similar AMR gene, virulence gene, and plasmid replicon profiles, support that these clusters represent outbreaks, and that nosocomial transmission contributes heavily to invasive Klebsiella infections. The outbreaks mostly involved ESBL lineages but no carbapenemaseproducers.

\section{DISCUSSION}

This report on the population structure of Klebsiella in 3 tertiary hospitals addresses critical knowledge gaps regarding the characteristics of $K$. pneumoniae in Nigeria and presents $5 \mathrm{~K}$. quasipneumoniae genomes, which without WGS cannot be differentiated from K. pneumoniae in our setting, even at reference laboratory level. Ours and other data reveal that multiple $K$. quasipneumoniae lineages, including resistant ones, circulate in Nigeria [9]. We also corroborate 
previous reports on the diversity of K. pneumoniae, which pose challenges as well as opportunities for curtailing and combating this pathogen $[29,30]$.

The high prevalence genes conferring resistance to fluoroquinolones and extended-spectrum $\beta$ lactams, last-line options for Nigeria's least affluent patients, in the most common lineages, reported here is of concern in spite of relatively low rates of carbapenem resistance in our setting, or elsewhere in Africa, compared to other countries [15, 31, 32, 33]. Moreover, while uncommon in this study,

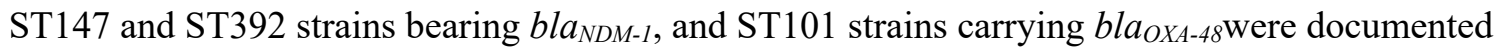
[37]. All these lineages deserve close and careful monitoring in national prospective surveillance, and further work is necessary to identify and track mobile elements they carry. The preponderance of plasmids in the Klebsiella strains sequenced reflects the known propensity of this genus to harbor and diversify mobile elements in the face of high selective pressure and has implications for resistance in the many species to which K. pneumoniae transmits DNA [2, 34].

Clonal group (CG) 307 is believed to be displacing the notorious CG258 as a primary lineage in South Africa, Italy, Colombia, and the USA, and it may be more virulent [31, 36-40]. The high ST307 frequency here, and in Malawiand South Africa, may explain the low overall prevalence of carbapenem resistance we observed compared to other locations [14, 17, 32, 35]. We recorded 21 ST307 isolates, but no ST258 isolates, and only 7 CG258 isolates -5 ST340 and 2 ST11. Clusters of likely clonal isolates within clonal complexes 15, 25, 17, ST5241, 392, and 101 were identified among retrospective isolates from OAU, the most sampled sentinel site, within clonal complexes, 15, 25, and 17, as well as ST307, ST5241, 392, and 101. The close genetic distances observed within 4 of these clones ( $<4$ pairwise SNP differences in each case) and the similar or identical resistance, virulence, and plasmid replicon profiles, and temporal clustering of their isolation strongly suggest that each of these clusters represents a retrospectively identified outbreak. As fewer retrospective isolates were stored at the other two institutions, we cannot rule out similar occurrences that are below our limits of detection. Outbreaks were caused by highly resistant lineages such as the ST17 cluster, but also more sensitive ones like the ST5241 and ST307 K. pneumoniae clusters. While outbreaks can sometimes be detected by phenotypic testing in diagnostic labs alone, the minimal biochemical and narrow disc diffusion test repertoires employed at sentinel labs, which underlie many 
species' misidentifications (Supplementary Table 1), make detection unlikely when the number of outbreak isolates is small. Our data show that, as in countries with more intensive surveillance, outbreaks likely commonly occur within health facilities in Nigeria and elsewhere in West Africa and will typically be missed without genomic support $[7,12,42,43]$. OAU and UCH currently provide subsidized blood culture for many patients, but most Nigerian facilities with blood culture do not, and health insurance coverage is low. Therefore, identifying outbreaks is likely to be curtailed by patients' inability to pay. Our data reveal that recent efforts to strengthen Nigeria's AMR response and boost infection prevention and control could be mutually enhancing if blood culture of routine febrile patient blood culture is facility-supported, and if prospective genomic surveillance is used.

This study has some limitations. First, very few archival isolates from only 3 facilities were available, and epidemiological data were incomplete. Furthermore, the sequence types observed here were sampled only from invasive infections. Nonetheless, this study represents an important starting point for documenting Klebsiella lineages, and we will build on these findings with prospective surveillance at more hospitals in southwestern Nigeria, which have now been enrolled in the national surveillance system.

\section{CONCLUSION}

We have detailed the characteristics of Klebsiella isolates from 3 southwestern hospitals in Nigeria. In addition to incorporating Nigeria-derived data into global phylogeographies of multidrug-resistant $K$. pneumoniae, our findings point to the significance of ST307 in Nigeria. Carbapenem-resistant STs 147 and 392, as well as novel ST5241 K. pneumoniae, may also represent future surveillance priorities for southwestern Nigeria. We have shown the benefits of public health genomic surveillance of pathogens - in particular, the potential for outbreak identification. Infection prevention and control is a key pillar of Nigeria's AMR National Action Plan and the data from this paper suggest that genomic surveillance and IPC implementation could be mutually reinforcing in this collaboration among scientists, health institutions, and the public health authority in Nigeria. 


\section{ACKNOWLEDGMENTS}

Members of the NIHR Global Health Research Unit for the Genomic Surveillance of Antimicrobial Resistance: Khalil Abudahab, Harry Harste, Dawn Muddyman, Ben Taylor, and Nicole Wheeler of the Centre for Genomic Pathogen Surveillance, Big Data Institute, University of Oxford, Old Road Campus, Oxford, United Kingdom and Wellcome Genome Campus, Hinxton, UK; Pilar DonadoGodoy, Johan Fabian Bernal, Alejandra Arevalo, Maria Fernanda Valencia, and Erik C. D. Osma Castro of the Colombian Integrated Program for Antimicrobial Resistance Surveillance - Coipars, CI Tibaitatá, Corporación Colombiana de Investigación Agropecuaria (AGROSAVIA), Tibaitatá Mosquera, Cundinamarca, Colombia; K. L. Ravikumar, Geetha Nagaraj, Varun Shamanna, Vandana Govindan, Akshata Prabhu, D. Sravani, M. R. Shincy, Steffimole Rose, and Ravishankar K.N of the Central Research Laboratory, Kempegowda Institute of Medical Sciences, Bengaluru, India; Jolaade J Ajiboye of the Department of Pharmaceutical Microbiology, Faculty of Pharmacy, University of Ibadan, Oyo State, Nigeria; Celia Carlos, Marietta L. Lagrada, Polle Krystle V. Macaranas, Agnettah M. Olorosa, June M. Gayeta, and Elmer M. Herrera of the Antimicrobial Resistance Surveillance Reference Laboratory, Research Institute for Tropical Medicine, Muntinlupa, the Philippines; Ali Molloy, alimolloy.com; John Stelling, The Brigham and Women's Hospital; and Carolin Vegvari, Imperial College London.

We sincerely appreciate technical assistance from sentinel site staff as well as Ifeoluwa Akintayo, Ifeoluwa Komolafe, and Faith Ifeoluwa Popoola. We also thank the team of curators of the Institut Pasteur MLST/cgMLST databases for curating the data and making them publicly available at https://bigsdb.pasteur.fr. We thank Lucy Goodchild for editorial assistance. 


\section{REFERENCES}

1. Podschun R, Ullmann U. Klebsiella spp. as nosocomial pathogens: Epidemiology, taxonomy, typing methods, and pathogenicity factors. Clin. Microbiol. Rev. 1998; 11: 589-603.

2. Wyres KL, Holt KE. Klebsiella pneumoniae Population Genomics and Antimicrobial-Resistant Clones. Trends Microbiol. 2016; 24: 944-956.

3. Wyres KL, Nguyen TNT, Lam MMC, et al. Genomic surveillance for hypervirulence and multidrug resistance in invasive Klebsiella pneumoniae from South and Southeast Asia. Genome Med. 2020; $12(1): 11$.

4. Olalekan A, Onwugamba F, Iwalokun B, Mellmann A, Becker K, Schaumburg F. High proportion of carbapenemase-producing Escherichia coli and Klebsiella pneumoniae among extended-spectrum $\beta$-lactamase-producers in Nigerian hospitals. J Glob Antimicrob Resist 2020; 21: 8-12.

5. Müller-Schulte E, Tuo MN, Akoua-Koffi C, Schaumburg F, Becker SL. High prevalence of ESBLproducing Klebsiella pneumoniae in clinical samples from central Côte d'Ivoire. Int J Infect Dis 2020; 91: 207-209.

6. Musicha P, Cornick JE, Bar-Zeev N, et al. Trends in antimicrobial resistance in bloodstream infection isolates at a large urban hospital in Malawi (1998-2016): a surveillance study. Lancet Infect Dis 2017; 17: 1042-1052.

7. Okomo U, Senghore M, Darboe S, et al. Investigation of sequential outbreaks of Burkholderia cepacia and multidrug-resistant extended spectrum $\beta$-lactamase producing Klebsiella species in a West African tertiary hospital neonatal unit: a retrospective genomic analysis. The Lancet Microbe 2020; 1: e119-e129.

8. Mbelle NM, Feldman C, Sekyere JO, Maningi NE, Modipane L, Essack SY. Pathogenomics and Evolutionary Epidemiology of Multi-Drug Resistant Clinical Klebsiella pneumoniae Isolated from Pretoria, South Africa. Sci Rep 2020; 10. 
9. Brinkac LM, White R, D’Souza R, Nguyen K, Obaro SK, Fouts DE. Emergence of New Delhi Metallo- $\beta$-Lactamase (NDM-5) in Klebsiella quasipneumoniae from Neonates in a Nigerian Hospital. mSphere 2019; 4.

10. Nejad SB, Allegranzi B, Syed SB, Ellisc B, Pittetd D. Health-care-associated infection in Africa: a systematic review. Bull. World Health Organ. 2011; 89: 757-765.

11. Irek EO, Amupitan AA, Obadare TO, Aboderin AO. A systematic review of healthcare-associated infections in Africa: An antimicrobial resistance perspective. Afr. J. Lab. Med. 2018; 7.

12. David S, Reuter S, Harris SR, et al. Epidemic of carbapenem-resistant Klebsiella pneumoniae in Europe is driven by nosocomial spread. Nat Microbiol. 2019; 4(11): 1919-1929.

13. Perdigão J, Modesto A, Pereira AL, et al. Whole-genome sequencing resolves a polyclonal outbreak by extended-spectrum beta-lactam and carbapenem-resistant Klebsiella pneumoniae in a Portuguese tertiary-care hospital. Microb Genomics 2020; mgen000349.

14. Musicha P, Msefula CL, Mather AE, et al. Genomic analysis of Klebsiella pneumoniae isolates from Malawi reveals acquisition of multiple ESBL determinants across diverse lineages. $J$ Antimicrob Chemother 2019; 74: 1223-1232.

15. Sonda T, Kumburu H, van Zwetselaar M, et al. Molecular epidemiology of virulence and antimicrobial resistance determinants in Klebsiella pneumoniae from hospitalised patients in Kilimanjaro, Tanzania. Eur J Clin Microbiol Infect Dis 2018; 37: 1901-1914.

16. Rakotondrasoa A, Passet V, Herindrainy P, et al. Characterization of Klebsiella pneumoniae isolates from a mother-child cohort in Madagascar. J Antimicrob Chemother 2020; 75: 1736-1746. 17. Argimón S, David S, Underwood A, et al. Rapid Genomic Characterization and Global Surveillance of Klebsiella Using Pathogenwatch. Clin Infect Dis 2021;73: In this supplement 18. Nigeria Centre for Disease Control (NCDC). National Action Plan for Antimicrobial Resistance 2017-2022. 2017. Available at:

https://ncdc.gov.ng/themes/common/docs/protocols/77_1511368219.pdf. Accessed June 10, 2021. 19. National Centre for Disease Control. NCDC Annual Report 2018. 2019; 1-74. Available at: https://ncdc.gov.ng/themes/common/files/annualreports/18803aba62a09ada4ad84c8db76c22ea.pdf. Accessed June 10, 2021. 
20. O’Brien TF, Stelling JM. WHONET: an information system for monitoring antimicrobial resistance. Emerg Infect Dis 1995; 1: 66.

21. Magiorakos AP, Srinivasan A, Carey RB, et al. Multidrug-resistant, extensively drug-resistant and pandrug-resistant bacteria: An international expert proposal for interim standard definitions for acquired resistance. Clin Microbiol Infect 2012; 18: 268-281.

22. CLSI. M100 Performance Standards for Antimicrobial Susceptibility Testing A CLSI supplement for global application. Performance Standards for Antimicrobial Susceptibility Testing Performance Standards for Antimicrobial Susceptibility Testing. 2020; Available at: https://www.academia.edu/41587236/M100_Performance_Standards_for_Antimicrobial_Susceptibilit y_Testing_A_CLSI_supplement_for_global_application_28th_Edition. Accessed June 10, 2021. 23. Lam MMC, Wyres KL, Judd LM, et al. Tracking key virulence loci encoding aerobactin and salmochelin siderophore synthesis in Klebsiella pneumoniae. Genome Med 2018; 10: 77.

24. Lam MMC, Wick RR, Wyres KL, et al. Genetic diversity, mobilisation and spread of the yersiniabactin-encoding mobile element ICEKp in Klebsiella pneumoniae populations. Microb Genomics 2018; 4: e000196.

25. Diancourt L, Passet V, Verhoef J, Grimont PAD, Brisse S. Multilocus sequence typing of Klebsiella pneumoniae nosocomial isolates. J Clin Microbiol 2005; 43: 4178-4182.

26. Irrgang A, Falgenhauer L, Fischer J, et al. CTX-M-15-producing E. coli isolates from food products in Germany are mainly associated with an IncF-type plasmid and belong to two predominant clonal E. coli lineages. Front Microbiol 2017; 8.

27. Agyekum A, Fajardo-Lubián A, Ansong D, Partridge SR, Agbenyega T, Iredell JR. blaCTX-M-15 carried by IncF-type plasmids is the dominant ESBL gene in Escherichia coli and Klebsiella pneumoniae at a hospital in Ghana. Diagn Microbiol Infect Dis 2016; 84: 328-333.

28. Logan LK, Weinstein RA. The epidemiology of Carbapenem-resistant enterobacteriaceae: The impact and evolution of a global menace. J Infect Dis 2017; 215: S28-S36.

29. Brisse S, Fevre C, Passet V, et al. Virulent clones of Klebsiella pneumoniae: Identification and evolutionary scenario based on genomic and phenotypic characterization. PLoS One 2009; 4. 
bioRxiv preprint doi: https://doi.org/10.1101/2021.06.21.44925. this version posted June 24 2021. The copyriaht holder for this preprint (which was not certified by peer review) is the author/funder, who has granted bioRxiv a license to display the preprint in perpetuity. It is made available under aCC-BY 4.0 International license.

30. Bialek-Davenet S, Criscuolo A, Ailloud F, et al. Genomic Definition of Hypervirulent and Multidrug-Resistant Klebsiella pneumoniae Clonal Groups. Emerg Infect Dis 2014; 20: 1812-1820.

31. Choi M, Hegerle N, Nkeze J, et al. The Diversity of Lipopolysaccharide (O) and Capsular Polysaccharide (K) Antigens of Invasive Klebsiella pneumoniae in a Multi-Country Collection. Front Microbiol 2020; 11.

32. Saavedra SY, Bernal JF, Montilla-Escudero E, et al. Complexity of Genomic Epidemiology of Carbapenem-Resistant Klebsiella pneumoniae Isolates in Colombia Urges the Reinforcement of Whole Genome Sequencing-Based Surveillance Programs. Clin Infect Dis 2021;73: In this supplement

33. Nagaraj G, Shammana V, Govindan V, et al. High-Resolution Genomic Profiling of CarbapenemResistant Klebsiella pneumoniae Isolates: A Multicentric Retrospective Indian Study. Clin Infect Dis 2021;73: In this supplement

34. Wein T, Wang Y, Hülter NF, Hammerschmidt K, Dagan T. Antibiotics Interfere with the Evolution of Plasmid Stability. Curr Biol 2020; 30.

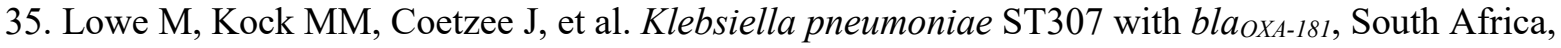
2014-2016. Emerg Infect Dis 2019; 25: 739-747.

36. Villa L, Feudi C, Fortini D, et al. Diversity, virulence, and antimicrobial resistance of the KPCproducing KlebsiellaK pneumoniae ST307 clone. Microb Genomics 2017; 3: e000110.

37. Geraci DM, Bonura C, Giuffrè M, et al. Is the monoclonal spread of the ST258, KPC-3-producing clone being replaced in southern Italy by the dissemination of multiple clones of carbapenem-nonsusceptible, KPC-3-producing Klebsiella pneumoniae? Clin. Microbiol. Infect. 2015; 21: e15-e17. 38. Ocampo AM, Chen L, Cienfuegos A V, et al. A two-year surveillance in five Colombian tertiary care hospitals reveals high frequency of non-CG258 clones of carbapenem-resistant Klebsiella pneumoniae with distinct clinical characteristics. Antimicrob Agents Chemother 2016; 60: 332-342. 39. Castanheira M, Farrell SE, Wanger A, Rolston K V., Jones RN, Mendes RE. Rapid Expansion of KPC-2-Producing Klebsiella pneumoniae Isolates in Two Texas Hospitals due to Clonal Spread of ST258 and ST307 Lineages. Microb Drug Resist 2013; 19: 295-297. 
40. Long SW, Olsen RJ, Eagar TN, et al. Population genomic analysis of 1,777 extended-spectrum beta-lactamase-producing Klebsiella pneumoniae isolates, Houston, Texas: Unexpected abundance of clonal group 307. MBio 2017; 8 .

41. Chen L, Mathema B, Pitout JDD, DeLeo FR, Kreiswirth BN. Epidemic Klebsiella pneumoniae ST258 is a hybrid strain. MBio 2014; 5 .

42. Argimón S, Masim MAL, Gayeta JM, et al. Integrating whole-genome sequencing within the National Antimicrobial Resistance Surveillance Program in the Philippines. Nat Commun 2020; 11 : $1-15$.

43. Carlos CC, Masim MAL, Lagrada ML, et al. Genome Sequencing Identifies Previously Unrecognized Klebsiella pneumoniae Outbreaks in Neonatal Intensive Care Units in the Philippines. Clin Infect Dis 2021;73: In this supplement 


\section{FIGURE LEGENDS}

Figure 1. Sequence Types of Klebsiella pneumoniae and their distribution across the 3 sentinel sites.

Figure 2. Epidemiological data, virulence determinants, antibiotic profile (phenotypic resistance), and antimicrobial resistance determinants in K. pneumoniae genomes ordered by phylogeny. The heat map shows the presence (red) or absence (blank) of virulence determinants, phenotypic resistance, AMR genes, and plasmid replicon genes. Tree nodes represent the origin of isolate collection. The shape of the tree nodes depicts the outbreak (star) and non-outbreak (circle) isolates. The data are available at https://microreact.org/project/GHRUNigeriaKpneumoniae/2a856694.

Figure 3: The timeline of likely outbreak of K. pneumoniae clones belonging to STs 17 (a), 25 (b), 307(c), and 5241(d) from the OAU sentinel site. The shape of the tree nodes depicts the outbreak (star) and non-outbreak (circle) isolate, while the color of the tree nodes depicts the sentinel site. The data are available at https://microreact.org/project/brfq17BXzwmqptfcrNRfZR/71b2f0f1 (ST17), https://microreact.org/project/8FP4F1D5fSQMv6FDxbR39b/bd381f0b (ST25), https://microreact.org/project/sV5NsJ8szcorvFAeFQgV4E/6498edf1 (ST307), and https://microreact.org/project/u5RPX7CjyitjRYMQ9ByW4W/1a3570e2 (ST5241). 
bioRxiv preprint doi: https://doi.org/10.1101/2021.06.21.449255; this version posted June 24, 2021. The copyright holder for this preprint (which was not certified by peer review) is the author/funder, who has granted bioRxiv a license to display the preprint in perpetuity. It is made available under aCC-BY 4.0 International license.

\section{FIGURES}

Figure 1.

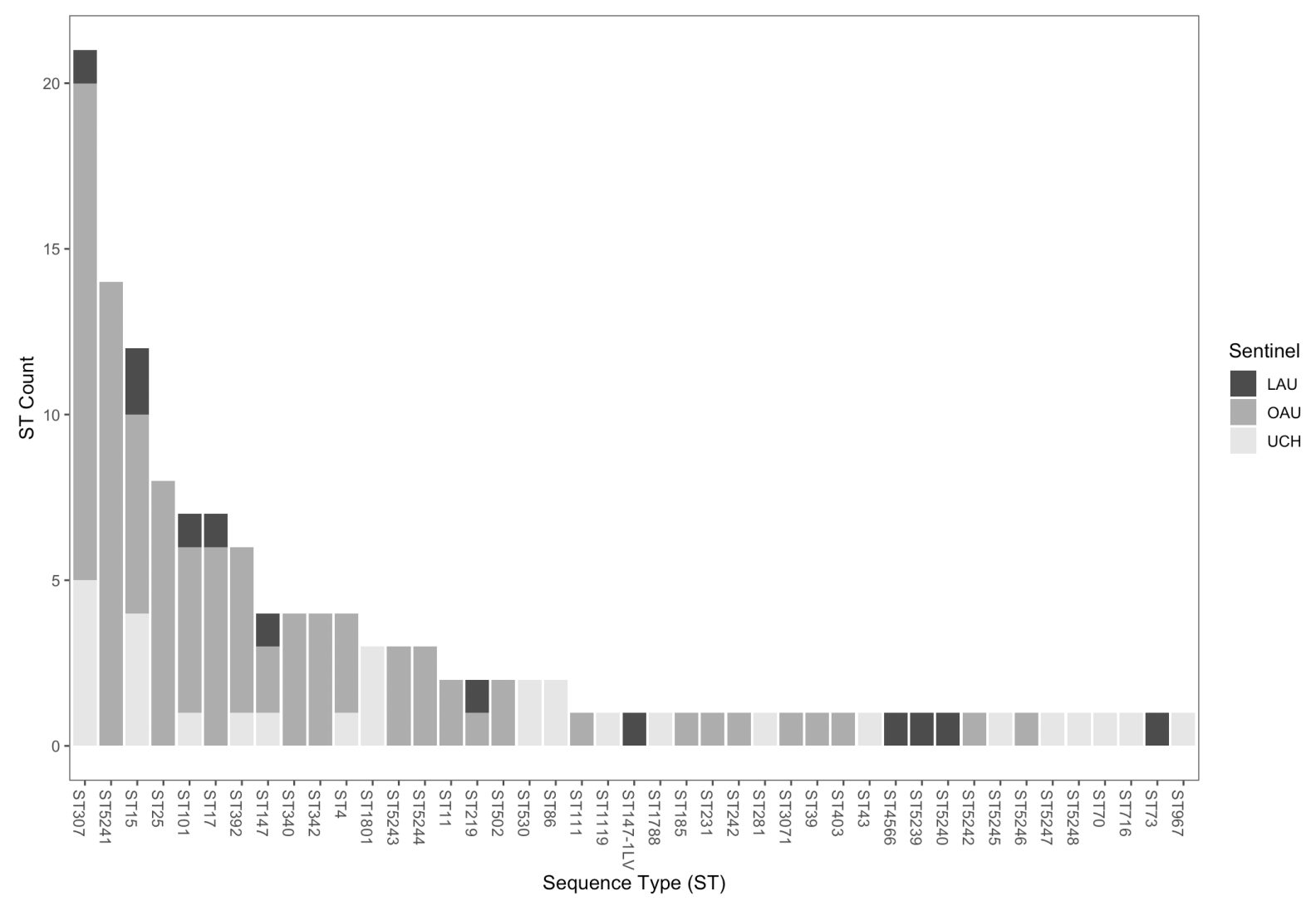

Key (LAU = Ladoke Akintola University Teaching Hospital, OAU = Obafemi Awolowo University Teaching Hospital, UCH = University College Hospital). 
bioRxiv preprint doi: https://doi.org/10.1101/2021.06.21.449255; this version posted June 24, 2021. The copyright holder for this preprint (which was not certified by peer review) is the author/funder, who has granted bioRxiv a license to display the preprint in perpetuity. It is made available under aCC-BY 4.0 International license.

Figure 2.

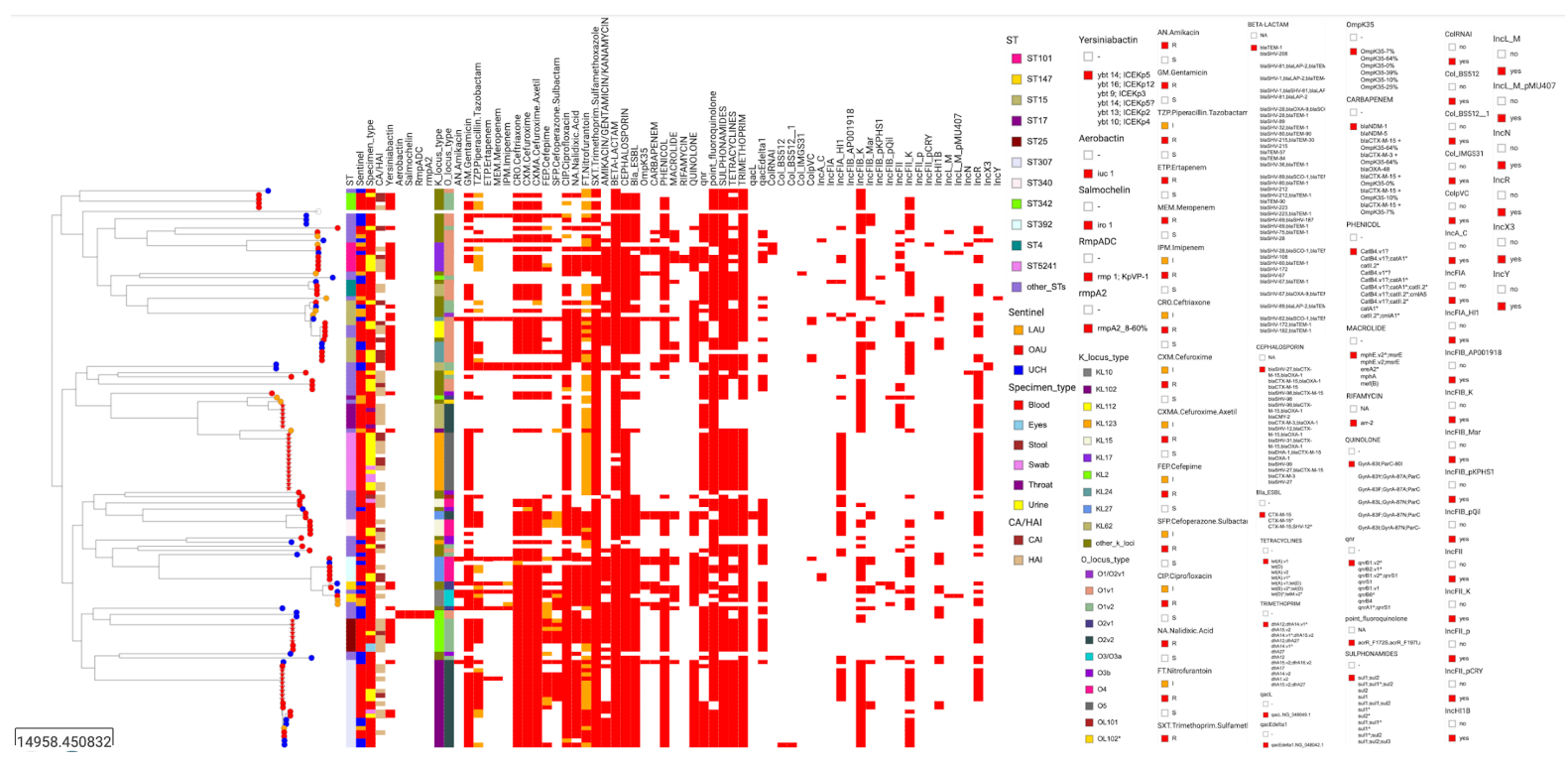


bioRxiv preprint doi: https://doi.org/10.1101/2021.06.21.449255; this version posted June 24, 2021. The copyright holder for this preprint (which was not certified by peer review) is the author/funder, who has granted bioRxiv a license to display the preprint in perpetuity. It is made available under aCC-BY 4.0 International license.

Figure 3:

(a)

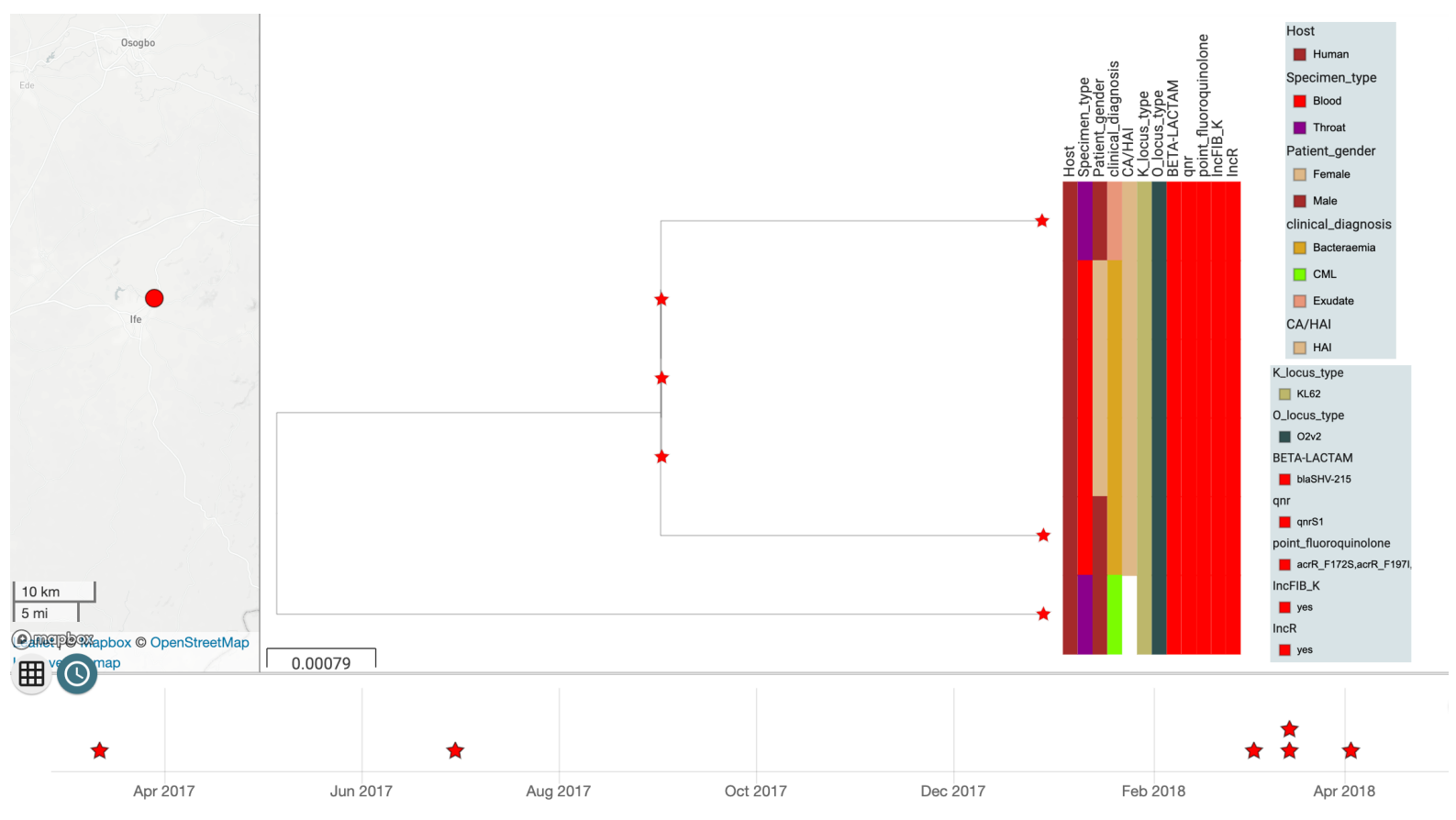

(b)

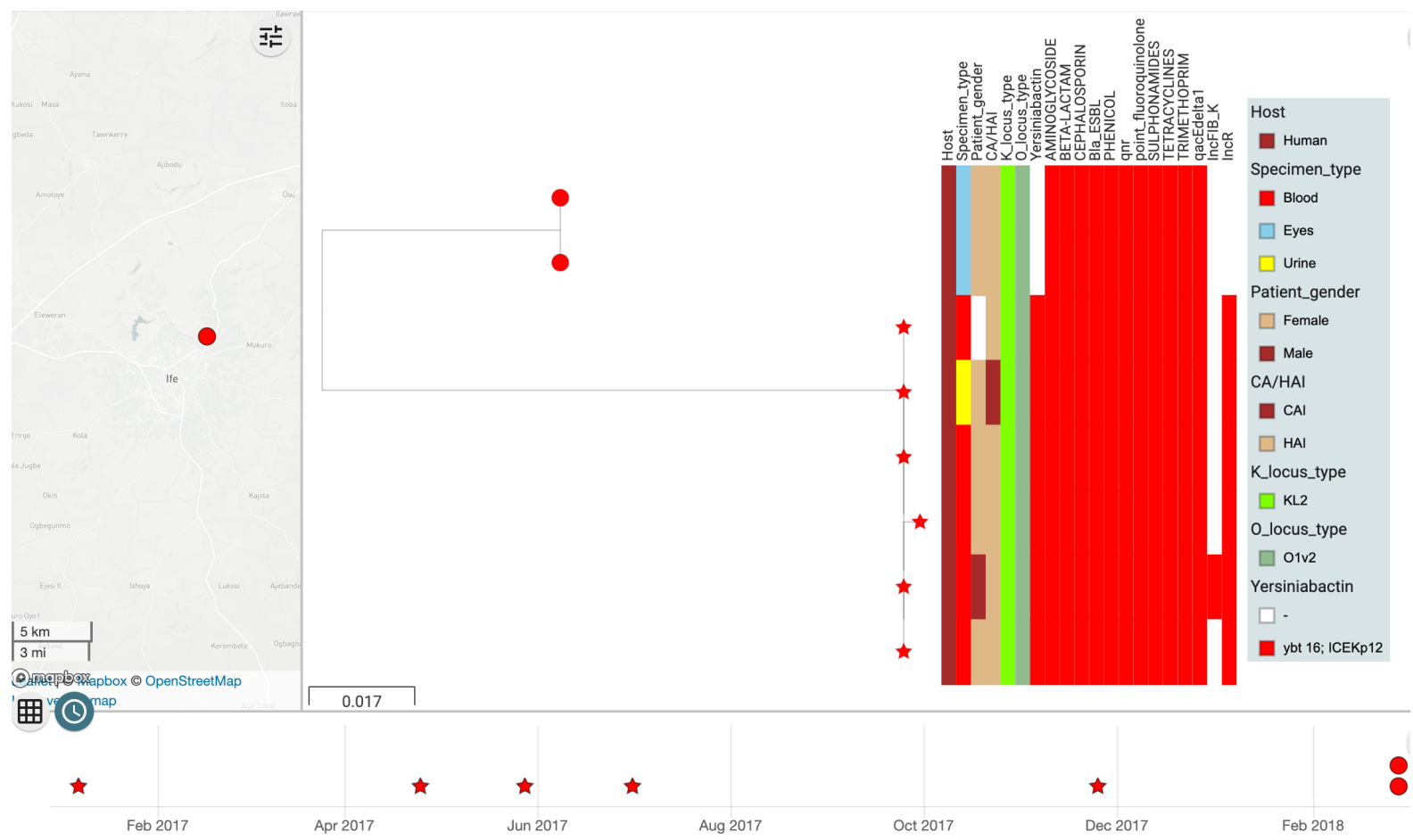


bioRxiv preprint doi: https://doi.org/10.1101/2021.06.21.449255; this version posted June 24, 2021. The copyright holder for this preprint (which was not certified by peer review) is the author/funder, who has granted bioRxiv a license to display the preprint in perpetuity. It is made available under aCC-BY 4.0 International license.

(c)

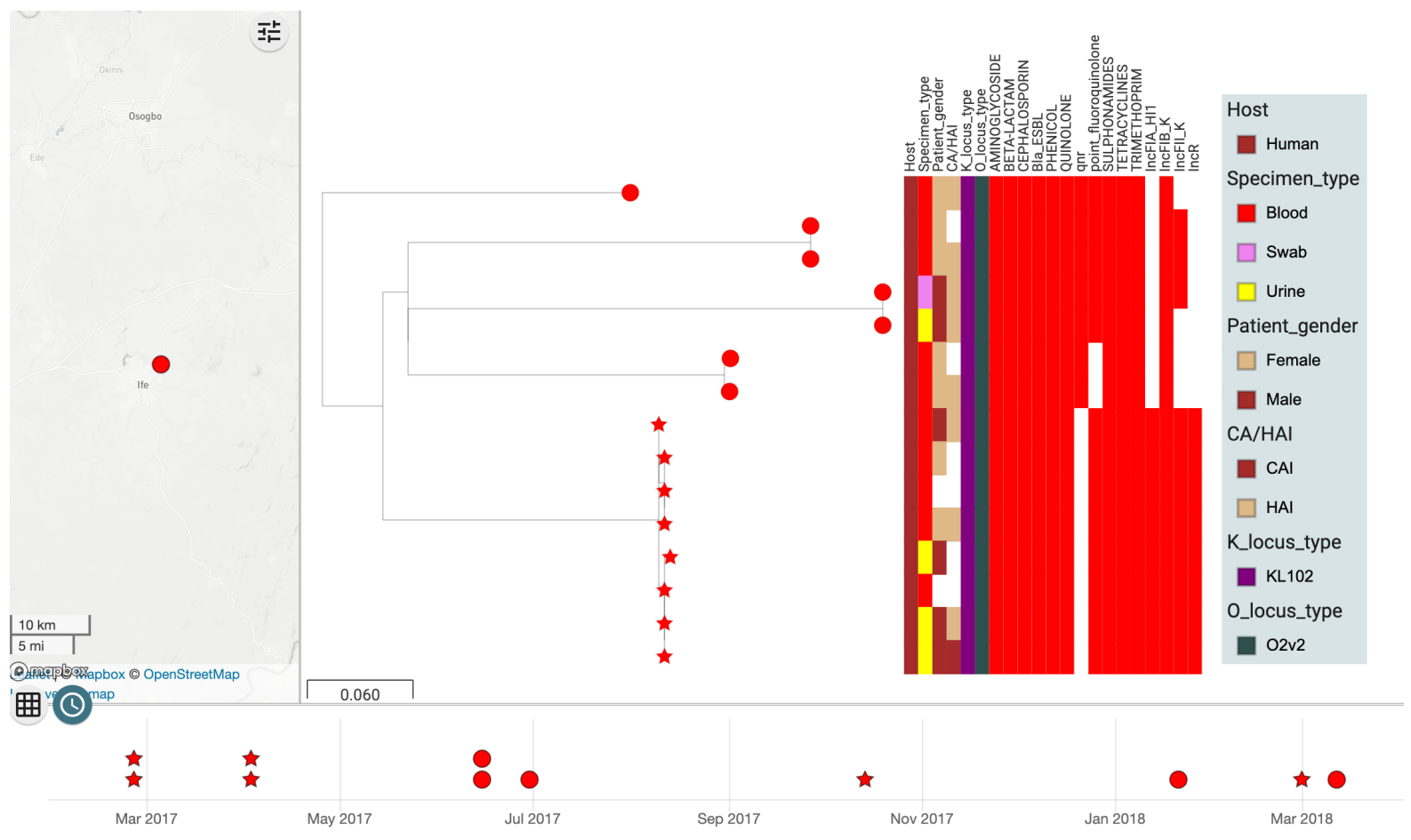

(d)

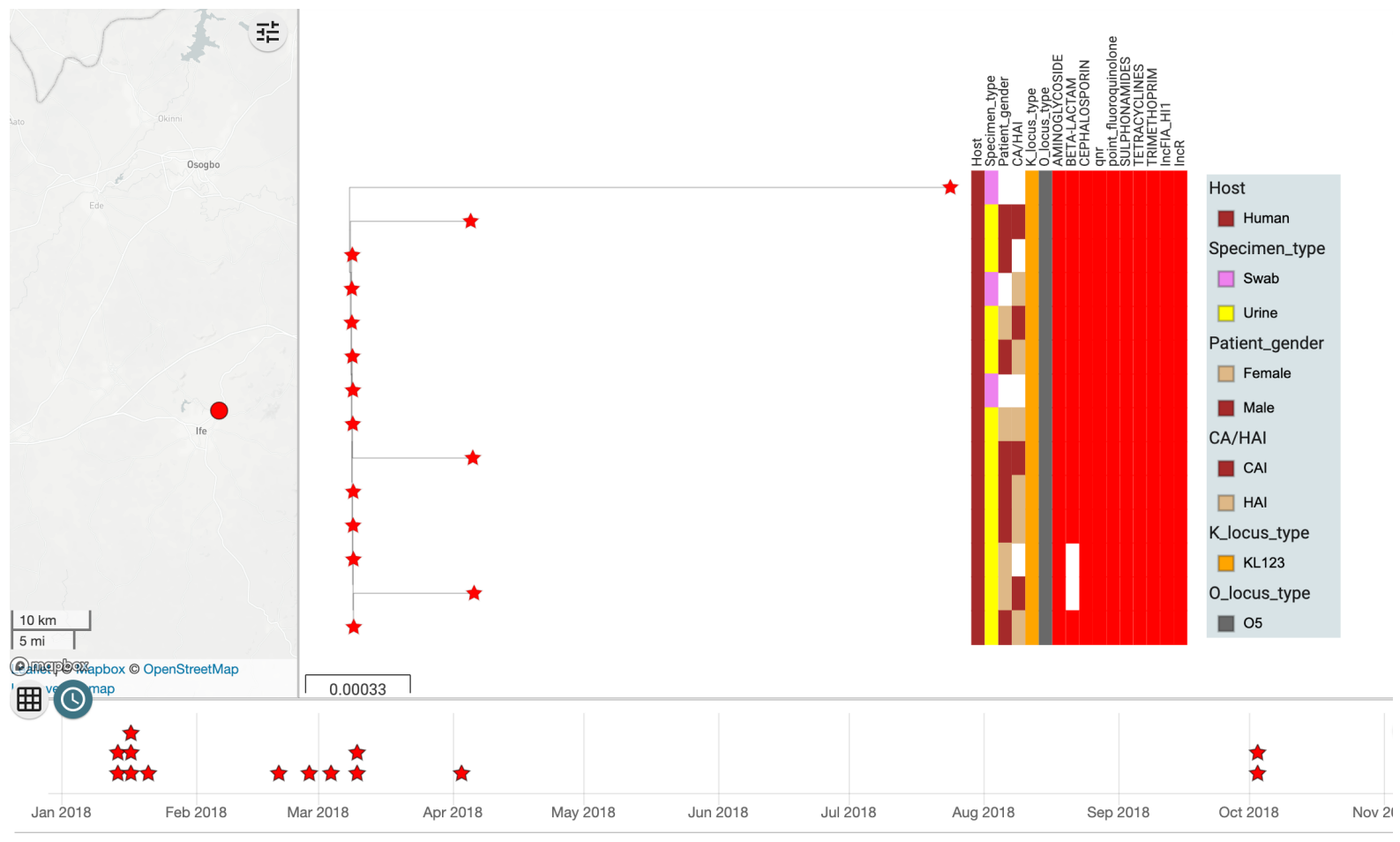

